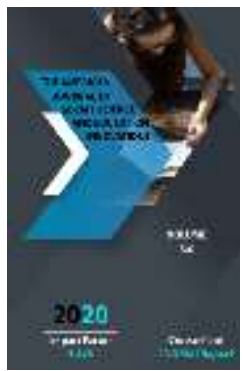

\title{
Semantic Grammatical Opportunities Of Descriptive And Imitative Units In Uzbek Languages
}

\author{
Aliboeva Nilufar Makhamatali Kizi \\ Teacher Of Kokand State Pedagogical Institute, Uzbekistan
}

Journal Website: http://usajournalshub.c om/index,php/tajssei

Copyright: Original content from this work may be used under the terms of the creative commons attributes 4.0 licence.

\section{ABSTRACT}

This article entails imitative expressions to sound and state in national linguistic view of the world, agglutinative languages, particulary, wide usage of imitations in Uzbek, additionally, almost nonexistence of imitations as an independent part of speech expressing imitation to sound and state with nouns, adjectives or verbs, derivation of imitation with the above words.

\section{KEYWORDS}

Imitation, descriptive word, descriptive expression, onomatopoeia, descriptive means, noun, verb, grammar form, imitation to sound and state, agglutination.

\section{INTRODUCTION}

The versatility of the phonetic structure of language is undoubtedly evident in its ability to express all the sounds in existence in terms of the ability of the speaker to hear and listen. In this sense, the phonetic structure of the Uzbek language is distinguished by its polyfunctionlity and wide coverage, which is observed in the expression of descriptive and imitative meaning of polyphony. Indeed, unlike other lexical categories that exist in a language, words that mean image and imitation are unlikely and even impossible to assimilate from other languages. The formation of descriptive words depends on how the representative of the language perceives reality in his mind, how he hears sounds, how he expresses it in the vowel sounds present in his language.

The lexical units that emerge as a result of these organic processes form a specific and literally national and unique layer of each 
language. In this sense, it is impossible not to emphasize the predominance of the Uzbek language, which belongs to the group of agglutinative languages. This is because, unlike other languages, including English, Uzbek can cover almost all the sounds that occur in nature. This, in turn, makes the words that imitate sound and action, the image of the situation, more natural.

It also completely dispels the stereotype that images and imitations are mainly used in children's poetry, and clearly proves that they are a means of substantive artistic imagery. Another peculiarity of imitation words is their multiplicity of meanings:

1. The soup boiled in a flash - tears dripped from his eyes;

2. The sea glows in the sunlight - the market is very busy, people are quiet.

In the examples we can see that a descriptive expression can also be used in different grammatical systems and, at the same time, serve to express different meanings. Of course, in this polysemy it is expedient to proceed from the context of reality, that is, from the general context of the text or speech, which is descriptively expressed in the understanding of the relevant meaning.

\section{MATERIALS AND METHODS}

Descriptive expressions can be used in a variety of syntactic functions in speech. In particular, we have seen in the examples above that a descriptive expression can serve as a cut or a case. At the same time, the units of expression of the image are also used in the function of determiner, representing a single sign that illuminates its essence, rather than the characteristic character of the word in the possessive or complementary function that comes with it. At this point, it can be said that descriptive expression determinants in some sense create a small synecdoche. That is, it takes only one property from the general characteristic, and thus points to the whole quality. For example: Outside, the cold wind blows, and the shirt shines in the sunlight. The units of figurative expression can also come as a mediator and an indirect complement: He now seeks to return the ready-made laughter if he is not shot from within, and says to his friend, "Stop, my dear, stop now," and straightens his breath; Mavlono Turobi entered (Oybek, “Navoi”). Sheikh Bahlul, a servant waiting for his master, light a candle as a reminder of the horse's voice (Oybek, Navoi). For example: The mother did not care about her son's whining. The old man's head ached from the constant noise. Saida had suddenly forgotten the key.

The descriptive word serves to express the mode of action in the section to which it is attached when performing the function of the case, and reveals the essence of semantic confusion, giving information about the speed at which the action took place. For example: You cry, you sing like a girl without clothes on Eid, you sigh with your hand on your cigarette (Oybek, Navoi). It was as if the nightingale often drank tea, swallowed, and every sound that sounded like melted cast iron into Saidi's heart (A. Qahhor, Sarob).

Hence, the units of descriptive expression can perform not only the motivation in the sentence, but also an independent syntactic function, in which case the syntactic function of the units is changed by the use of adverbs. In all applications, either "image + imitation" or "imitation + image" has one of the most complex semantic meanings. In this case, the components of the complex essence conditionally represent the general formula of "basic meaning + adjoining meaning." 


\section{RESULT AND DISCUSSION}

The difference between imitation units and other lexemes in a language is that they reflect all the phonetic opportunities of the language, at a glance, sounds that do not occur together in the word structure may be innumerable in the example of imitation words. This, of course, is due to the fact that in the process of formation of imitation words, a person first observes the environment and forms words based on the phonetic potential of his language in the expression of certain sounds in it. In this sense, imitation words in the Uzbek language are distinguished by their maximum closeness to the sound of nature. Linguists analyze sound imitation words into several groups of their own. Depending on the object being imitated, such expressions include imitation of the sounds of living beings (humans and animals), imitations of the sounds of inanimate objects, as well as imitations of various sounds produced by movement or vibration.

Initially, linguists AN Kononov and A. Gulomov included descriptive expressions as well as imitative words, but later these two units of expression were classified under the category of descriptive words. However, linguists have reconsidered this theory and concluded that urges and imitations differ significantly from each other, and it is expedient to explain this conclusion as follows: "semantically, urges make the speaker feel more expresses excitement, command, call, and request. Some of their groups also represent attitudes to place and time, but this meaning is also emotional. "Descriptive words represent the sounds and actions of people and other objects as sounds or images of action. Emotions, commands, please, are not typical for descriptive words.

Indeed, categorizing imitation words as motivations was ignoring the fact that they were syntactic functional units, while completely denying their polyfunctional and polysemantic nature.

Linguists directly explain the imitation words in the modern Uzbek literary language as follows: "imitation words are formed on the basis of imitation of different sounds in existence, their repetition: tars-turs, qars-kurs, chars-churs, gumbur- like humming, chiy-chiy ".

One of the characteristic features of imitative units in Uzbek, as well as in many other languages, is that they often consist of a single syllable and are often used in a repetitive or double form. In this case, the use of repetition or double case not only emphasizes the action performed, but also in a sense refers to its style, ie the speed of execution: "In descriptive words, the repetitive form, in addition to amplifying sound or movement, , also indicates that the action is more than one, continuous. In repetition, repetition increases the emotion and strengthens the emotion."

\section{CONCLUSION}

Despite its polyfunctional and polysemantic nature, the use of imitation words in Uzbek is limited. The use of imitation units is mainly limited to riddles, proverbs, sayings, and examples of folklore. Although it can be an unparalleled means of imagery in fiction, imitations are relatively rare in works of art. And, in our opinion, there are two main reasons for this: First, although the phonetics of most sounds, the articulation of the speakers has almost no difficulty in pronouncing any combination of sounds and sounds, it is impossible to pronounce all the sounds in the Uzbek language in high similarity with the original. If it is possible to ideally imitate a sound, then the word becomes an imitation, not an imitation. "Imitations, of course, must be distinguished from imitation," he said. The immaturity of words in language is not entirely consistent with the sounds of nature, the fact 
Doi: https://doi.org/10.37547/tajssei/Volume02Issue08-34

that this complex of sounds is not the same as the sounds of nature, the sound of something in nature is imitated differently in different languages confirms. The phenomenon of imitating the sound of something different through different sound complexes - is not unique to different languages, but can be seen in languages belonging to the same family, and even in different dialects of the same language.

\section{REFERENCES}

1. Kungurov R. .-T: Subject, 1966

2. International Journal of Basic Sciences and Applied Research Vol, 3 (SP), 219-225, 2014//Available online athttp://www.isicenter.org.-P.221

3. www.wikipedia.org

4. www.hozir.org

5. www.kathysteinemann.com

6. www.tandfonline.com

7. www.academia.edu 